\title{
Relative Importance of Nesting Habitat and Measures of Connectivity in Predicting the Occurrence of a Forest Songbird in Fragmented Landscapes
}

\section{Importance relative de l'habitat de nidification et du degré de connectivité comme prédicteurs de l'occurrence d'un passereau forestier en paysages fragmentés}

\author{
$\underline{\text { Stephanie Melles }}^{1}$, Marie-Josée Fortin $^{2}, \underline{\text { Debbie Badzinski }}^{3}$ and $^{\text {Kathryn Lindsay }}{ }^{4}$
}

\begin{abstract}
Theoretical and empirical studies suggest that well-connected networks of forest habitat facilitate animal movement and contribute to species' persistence and thereby the maintenance of biodiversity. Many structural and functional connectivity metrics have been proposed, e.g., distance to nearest neighboring patch or graph-based measures, but the relative importance of these measures in contrast to nesting habitat at fine spatial scales is not well established. With graph-based measures of connectivity, Euclidean distances between forest patches can be directly related to the preferred gap crossing distances of a bird (functional connectivity). We determined the relative predictive power of nesting habitat, forest cover, and structural or functional connectivity measures in describing the breeding distribution of Hooded Warblers (Setophaga citrina) over two successive breeding seasons in a region highly fragmented by agriculture in southern Ontario. Logistic regression models of nesting occurrence patterns were compared using Akaike's information criterion and relative effect sizes were compared using odds ratios. Our results provide support for the expectation that nest-site characteristics are indeed related to the breeding distribution of S. citrina. However, models based on nesting habitat alone were 4.7 times less likely than a model including functional connectivity as a predictor for the breeding distribution of S. citrina. Models of nest occurrence in relation to surrounding forest cover had lower model likelihoods than models that included graph-based functional connectivity, but these measures were highly confounded. Graph-based measures of connectivity explained more variation in nest occurrence than structural measures of forest connectivity, in both 2004 and 2005. These results suggest that S. citrina selected nesting areas that were functionally connected at their preferred gap crossing distances, but nesting habitat was a critically important predictor of nest occurrence patterns.
\end{abstract}

RÉSUMÉ. Des recherches théoriques et empiriques laissent supposer que des réseaux de milieux forestiers bien connectés permettent le déplacement de la faune et contribuent à la pérennité d'une espèce et, par le fait même, au maintien de la biodiversité. De nombreuses mesures de connectivité structurelle et fonctionnelle ont été avancées, par exemple la distance à l'îlot voisin le plus proche ou encore, des mesures fondées sur des graphiques, mais l'importance relative de ces indices comparativement à l'habitat de nidification à des échelles spatiales fines n'est pas établie clairement. À partir de mesures de la connectivité fondées sur des graphiques, la distance euclidienne entre les îlots forestiers peut être directement reliée à la distance préférée de traversée d'une trouée par un oiseau (connectivité fonctionnelle). Nous avons déterminé la capacité prédictive relative de l'habitat de nidification, du couvert forestier et des mesures de connectivité structurelle et fonctionnelle pour décrire la répartition de nidification de la Paruline à capuchon (Setophaga citrina) au cours de deux saisons de nidification successives dans une région très fragmentée par l'agriculture, dans le sud de l'Ontario. Des modèles de régression logistique des tendances dans l'occurrence de nidification ont été comparés au moyen du critère d'information d'Akaike, et l'amplitude des effets relatifs a été évaluée à l'aide du risque relatif approché (odds ratio en anglais). Nos résultats corroborent les suppositions selon lesquelles les caractéristiques du site de nidification sont vraiment reliées à la répartition de nidification de $\mathrm{S}$. citrina. Toutefois, les modèles fondés sur l'habitat de nidification uniquement étaient 4,7 fois moins performants qu'un modèle qui comportait la connectivité fonctionnelle comme variable prédictive de la répartition de nidification de S. citrina. Les modèles fondés sur l'occurrence des nids en fonction du couvert forestier environnant étaient moins vraisemblables que les modèles qui incluaient la connectivité

\footnotetext{
${ }^{1}$ University of Toronto, ${ }^{2}$ Department of Ecology and Evolutionary Biology, University of Toronto, ${ }^{3}$ Ontario Program Manager Bird Studies Canada c/o Environment Canada, ${ }^{4}$ Wildlife and Landscape Science Directorate, Environment Canada
}

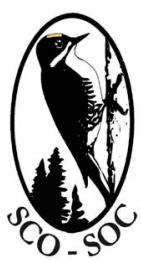

Sponsored by the Society of Canadian Ornithologists and Bird Studies Canada Parrainée par la Société des ornithologistes du Canada et Études d'oiseaux Canada

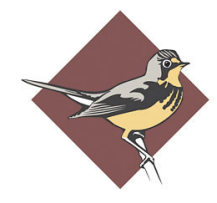

BIRD STUDIES CANADA 
fonctionnelle fondée sur des graphiques, mais ces mesures se confondaient grandement. Les mesures de la connectivité fondées sur des graphiques ont expliqué davantage de variations dans l'occurrence des nids que les mesures structurelles de la connectivité forestière, tant en 2004 qu'en 2005. Nos résultats donnent à penser que S. citrina sélectionne des milieux de nidification qui sont connectés fonctionnellement à leurs distances préférées de traversée d'une trouée, mais l'habitat de nidification s'est aussi avéré être une variable prédictive très importante des tendances dans l'occurrence des nids.

Key Words: forest fragmentation; graph-based network measures; Hooded Warbler; Setophaga citrina; spatial graphs

\section{INTRODUCTION}

Theoretical estimates, based on artificial landscape simulations, suggest that below $30 \%$ to $40 \%$ habitat cover, populations are broken up into a meta-population structure in which regional persistence may depend more on the configuration of habitat than on habitat cover alone (Andrén 1994, Fahrig 2001, With and King 2001). Below this theoretical threshold, simulated populations go extinct because small, fragmented populations are subject to stochastic extinction, and patch reoccupation rates are too low to maintain meta-population dynamics (With and King 2001). However, mensurative investigations into the relationship between structural measures of forest connectivity and breeding bird occurrence patterns provide inconsistent results, often indicating that overall forest amount is more important than forest configuration (McGarigal and McComb 1995, Trzcinski et al. 1999, Betts et al. 2006), or indicating that configuration has non-negligible effects (Villard et al. 1999). Issues with study design, e.g., matrix effects, and statistical difficulties have often prevented a clear distinction between the independent effects of habitat amount and configuration in many of these studies (Koper et al. 2007, Smith et al. 2009).

Birds are particularly well studied in the context of forest fragmentation, patch isolation, and connectivity (Bélisle et al. 2001, Desrochers et al. 2011). Studies that measured dispersal directly (Brooker et al. 1999, Cale 2003, Uezu et al. 2005) or studies that modeled dispersal on an individual basis (LeónCortés et al. 2003, Russell et al. 2003) tend to show that low levels of connectivity increase the risk of mortality and that birds are reluctant to cross relatively small, nonforest gaps (Desrochers and Hannon 1997, Norris and Stutchbury 2001, 2002). Thus empirical evidence based on bird movement and translocation experiments provide support for the importance of maintaining connectivity (Desroschers and Hannon 1997, Brooker et al. 1999), but evidence for critical habitat thresholds or clear configuration effects in large landscapes with low habitat cover remains sparse and inconclusive (reviewed by Swift and Hannon 2010). Some studies provide limited support for the existence of a threshold (e.g., Freemark and Collins 1992, Andrén 1994), but taken together, landscapelevel studies on threshold effects demonstrate variable results and are still limited in number (Swift and Hannon 2010).
Configuration effects are generally measured using a variety of structural metrics that quantify the size, shape, and location of habitat features on a landscape, e.g., nearest neighboring patch distances, mean and largest patch size, total edge. We refer to this type of metric for configuration effects as structural connectivity. Several authors have emphasized the need to link these structural metrics to their biological function or the actual movement abilities of animals within fragmented landscapes (Tischendorf and Fahrig 2000a,b, Brooks 2003, Fischer and Lindenmayer 2007). Very different landscapes often result in similar structural measures of landscape pattern (Hargis et al. 1998, Fortin et al. 2003), yet it is highly unlikely that movement patterns would be the same in different landscapes (Bélisle et al. 2001, Uezu et al. 2005).

Applications of graph-based measures of habitat connectivity attempt to link the structural and functional components of connectivity by measuring distances between habitat patches and relating those distances to the movement abilities of animals, connecting only those patches that are within an animal's movement abilities or preferences (Keitt et al. 1997, Urban and Keitt 2001, O'Brien et al. 2006). Euclidean distances between forest patches can be directly related to the preferred gap crossing distances of a bird; or crossing distances can be modified by the potential costs of traversing a variety of different barriers. Thus, the functional links between forest patches can be related to the associated 'costs' of dispersing through different matrix types because the intervening matrix may carry different mortality risks (Brooker et al. 1999, Brooker and Brooker 2002, Dunford and Freemark 2004), though few if any empirical estimates of mortality risk in different matrix types exist (Desrochers et al. 2011). We refer to graph-based metrics as functional connectivity. Graphbased measures of connectivity have an intuitive theoretical appeal for species at risk conservation planning (Urban and Keitt 2001), but they are just beginning to be tested in the field (Bunn et al. 2000, O'Brien et al. 2006, Fall et al. 2007).

Our study was designed to investigate how the breeding distribution of Hooded Warblers (Setophaga citrina) in forest patches was related to nest-site habitat data, surrounding forest cover, and surrounding forest connectivity estimated by either structural or functional measures of configuration. We address the question, are functional connectivity measures of forest connectivity better predictors of nesting occurrence than 
corresponding structural measures? In addition, we examine the relative importance of nest-site habitat, contextual forest cover, and connectivity metrics. With forest fragmentation, nesting habitat is lost as forest patches become smaller, but it is unlikely that the loss of suitable nesting habitat occurs linearly with forest loss. The loss of suitable nesting habitat could rather occur stochastically such that there is no guarantee a remaining small patch will contain a small proportion of suitable nesting habitat (Haila 1983, Betts et al. 2006). Availability of suitable nesting habitat is expected to be one of the primary constraints on nesting occurrence, irrespective of landscape context or functional connectivity.

It is becoming increasingly recognized that processes related to breeding-occupancy patterns and the persistence of a species in a region must be examined at multiple scales (Cushman and McGarigal 2003) because several processes may be related to the spatial distributions of species at regional extents. Field biologists have known for a long time that nestlevel habitat characteristics can determine whether or not an area is suitable for breeding by a particular species. If suitable breeding habitat is spatially isolated, however, it is likely to remain unoccupied. The patch and landscape characteristics surrounding nesting habitat provide several of the required conditions for breeding, such as the social environment required to attract a mate (Cale 2003), the resources needed for survival and breeding success (Haila 1983), and a spatial network of patches that facilitate dispersal to and from an area (Taylor et al. 1993).

Many empirical studies that examine the relative importance of habitat loss and fragmentation used measures of breeding evidence such as species occurrence, abundance, or diversity (reviewed by Swift and Hannon 2010), but these measures may not always reflect habitat quality or individual fitness (Van Horne 1983). In addition, there is a need for the use of statistical methods able to detect and distinguish between habitat amount and fragmentation effects (Swift and Hannon 2010). The novelty of our study is that we use nest occurrence data; we test for local, nest-site habitat effects; and we examine the relative importance of forest loss and configuration by comparing structural to functional measures of connectivity. We use standardized variables in logistic regression to examine the relative importance of these different predictors following the approach advocated by Smith et al. (2009) for linear regression to disentangle the effects of habitat loss and configuration.

\section{METHODS}

\section{Study area and patch selection}

The study area is a region of southern Ontario with mixedwood, eastern deciduous forests that is highly fragmented by agriculture. Much of the region is below $30 \%$ to $40 \%$ forest cover measured at a variety of spatial scales, e.g., within $1 \mathrm{~km}$,
$10 \mathrm{~km}$, or $20 \mathrm{~km}$ (Fig. 1). If the spatial configuration of forest patches on a landscape matters, human-dominated landscapes below the theoretical fragmentation threshold are ideal areas to test expectations about the effects of forest connectivity on patch occupancy and breeding occurrence patterns (Swift and Hannon 2010). Forest patches were selected based on a measure of graph-based connectivity such that isolated patches could be compared with highly connected patches. We selected forest patches across a range of sizes $(n=33$ total patches surveyed in the field over two years, 2004-2005; Fig. 1 ), ensuring that any confounding between patch-size and connectivity with surrounding patches was minimized in the study design (Ewers and Didham 2006).

Fig. 1. Area of study region $\left(\cong 1256 \mathrm{~km}^{2}\right)$ in southern Ontario (UTM Northing 4,715,834; Easting 521,808) showing all wooded areas in grey. Forested patches $(n=33)$ surveyed for $S$. citrina between 2004 and 2005 are outlined in black. Each patch is surrounded by a circular 'landscape' $2 \mathrm{~km}$ in diameter. Patches were selected within $20 \mathrm{~km}$ of the core population, St. Williams' Crown research forest (indicated by an ' $x$ ').

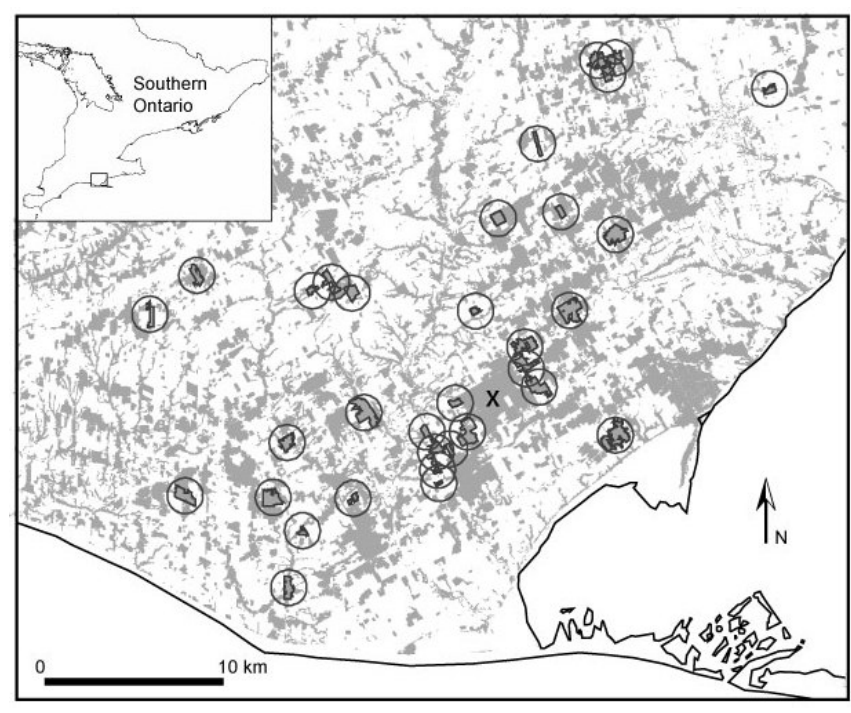

Ontario Base Maps (OBM 1996), wooded area layers $(1: 10,000)$, were used to delineate forest patches in an area within $20 \mathrm{~km}$ of the perimeter of St. Williams forest (Norfolk, Ontario), which is known to contain the 'core' population or highest known breeding densities of S. citrina in Canada (Friesen et al. 2000). The OBM is a compilation of historical and digital topographic information in Ontario acquired largely by aerial photography. Information on forested areas, therefore, is accurate to the date that the photography was acquired and this varies throughout the province. To ensure that forested polygons in our study area were accurate to current forest conditions, we corrected the polygons by 
Table 1. Variable codes and descriptions at different spatial extents for: nest-site vegetation characteristics, forest cover, structural and graph-based connectivity variables. (dbh $=$ diameter at breast height).

\begin{tabular}{|c|c|c|c|c|}
\hline Variables & Description & $\begin{array}{c}\text { Variable } \\
\text { Preprocessing }\end{array}$ & $\begin{array}{l}\text { Variable } \\
\text { acronyms }\end{array}$ & Extent \\
\hline shrub cover (low) & $\%$ shrub cover ( 0.5 and $1.3 \mathrm{~m}$ in height $) \mathrm{w} / \mathrm{in} 5 \mathrm{~m}$ & $\ln (\mathrm{p} /(1-\mathrm{p}))$ & SC513 & \multirow{11}{*}{$\begin{array}{c}\text { Nest-site variables } \\
\text { measured } \\
\text { within } 5 \mathrm{~m}\end{array}$} \\
\hline shrub cover (high) & $\%$ shrub cover ( 1.3 and $3 \mathrm{~m}$ in height) w/in $5 \mathrm{~m}$ & $\ln (p /(1-p))$ & SC133 & \\
\hline sapling cover & $\%$ sapling cover ( 3 and $10 \mathrm{~m}$ in height) w/in $5 \mathrm{~m}$ & $\ln (\mathrm{p} /(1-\mathrm{p}))$ & SC310 & \\
\hline basal area $\left(\mathrm{m}^{2} / \mathrm{ha}\right)$ & cross sectional tree area at breast height $(1.3 \mathrm{~m})^{\dagger}$ & none & $B A$ & \\
\hline canopy gap & canopy gap opening $($ length $\times$ width $\times \pi) / 4\left(\mathrm{~m}^{2}\right)$ & $\ln (x+1)$ & $C G$ & \\
\hline canopy height & maximum canopy height (m) & none & $\mathrm{CH}$ & \\
\hline live (sm. saplings) & $\#$ of live saplings $<2.5 \mathrm{~cm} \mathrm{dbh}$ & $\ln (x+1)$ & $s S$ & \\
\hline trees (lg. saplings) & \# of live saplings 2.5 to $9.9 \mathrm{~cm} \mathrm{dbh}$ & $\ln (x+1)$ & $l S$ & \\
\hline (small trees) & \# of live small trees 10 to $38 \mathrm{~cm} \mathrm{dbh}$ & none & $S T$ & \\
\hline (large trees) & live large trees $>38 \mathrm{~cm} \mathrm{dbh}$ & $(0 / 1)$ & $L T$ & \\
\hline distance to edge & distance to forest edge $\ddagger$ & none & $E D G E$ & \\
\hline forest cover & $\%$ forest cover w/in $1 \mathrm{~km}$ & $\ln (\mathrm{p} /(1-\mathrm{p}))$ & $F C$ & within $1 \mathrm{~km}$ \\
\hline nearest neighbor & distance to the nearest neighboring patch (m) & none & $N N$ & \multirow{7}{*}{$\begin{array}{c}\text { Structural } \\
\text { connectivity } \\
\text { measured } \\
\text { within } 1 \mathrm{~km}\end{array}$} \\
\hline total edge & total edge w/in $1 \mathrm{~km}(\mathrm{~m})$ & none & $T E$ & \\
\hline area largest patch & area largest patch w/in $1 \mathrm{~km}\left(\mathrm{~m}^{2}\right)$ & $\ln (x+1)$ & $L P A$ & \\
\hline search area & nest search area $\left(\mathrm{m}^{2}\right)$ & $\ln (x+1)$ & $S A$ & \\
\hline patch area & forest patch area $\left(\mathrm{m}^{2}\right)$ & $\ln (x+1)$ & $P A$ & \\
\hline mean patch area & mean forest patch area $\left(\mathrm{m}^{2}\right)$ & $\ln (x+1)$ & $M P A$ & \\
\hline number of patches & number of patches & none & $N P$ & \\
\hline area conn'd $<50$ & area $\left(\mathrm{m}^{2}\right)$ connected $\mathrm{w} / \mathrm{in}$ female dispersal $<50 \mathrm{~m}$ & none & $A C f$ & \multirow{5}{*}{$\begin{array}{c}\text { Functional (graph- } \\
\text { based) connectivity } \\
\text { measured within } 1 \\
\text { km }\end{array}$} \\
\hline patch import 50 & patch import to expected cluster size at $50 \mathrm{~m}$ & $\ln (\mathrm{p} /(1-\mathrm{p}))$ & $P I_{f}$ & \\
\hline area conn'd 500 & area connected $w /$ in male dispersal $<500 \mathrm{~m}$ & none & $A C_{m}$ & \\
\hline patch import 500 & patch import to expected cluster size at $500 \mathrm{~m}$ & $\ln (\mathrm{p} /(1-\mathrm{p}))$ & $P I_{m}^{m}$ & \\
\hline distance threshold & distance threshold $(\mathrm{m})$ connecting all patches & $\ln (x+1)$ & $D T^{m}$ & \\
\hline distance to core & distance $(\mathrm{km})$ to core population & $\ln (x+1)$ & $D C$ & Functional \\
\hline patch import 50 & patch import to expected cluster size at $50 \mathrm{~m}$ & $\ln (\mathrm{p} /(1-\mathrm{p}))$ & $R P I_{f}$ & connectivity within \\
\hline patch import 500 & patch import to expected cluster size at $500 \mathrm{~m}$ & $\ln (\mathrm{p} /(1-\mathrm{p}))$ & $R P I_{m}^{\prime}$ & $20 \mathrm{~km}$ \\
\hline
\end{tabular}

$\dagger$ Estimated using a factor 2 prism.

$\ddagger$ If $>25 \mathrm{~m}$, then mid-point of 25-50 m, 50-100 m, 100-200 m, and > $200 \mathrm{~m}$

manually digitizing changes to forested areas using digital aerial orthophotographs provided by Norfolk County, and acquired 24 April 2002 with an average horizontal positional error between 1 and $2 \mathrm{~m}$. Forested polygons were then converted to raster format with a grid cell resolution of $5 \mathrm{~m}$.

A forest patch was considered to be unique if it was separated from other forest patches by a road or other nonforested area $(\approx 25 \mathrm{~m})$. We recognize that this definition of a patch is somewhat arbitrary (Betts et al. 2006) because data suggest that males make regular extra-territory extrusions into neighboring patches (Norris and Stutchbury 2001). But female S. citrina are much more restricted during the breeding season (Norris and Stutchbury 2002), and generally the territorial boundaries of neotropical migrants track sharp forest edges (St-Louis et al. 2004) so $25 \mathrm{~m}$ breaks were considered appropriate.

\section{Bird surveys and nest sites}

S. citrina is a distinctive species that is easily surveyed by sight and song (Evans Ogden and Stutchbury 1994). In both 2004 and 2005, selected forest patches were surveyed by the first author and field assistants using playback recordings of conspecific male $S$. citrina songs. Each woodland was surveyed using playbacks every $500 \mathrm{~m}$ (duration 3-5 min) until the entire patch was covered (Fig. 1). Males responding to playbacks or heard singing in an area on at least two separate occasions, separated by a minimum of one week, were considered to be holding a territory. Territories were thoroughly searched for females with nests.

All sites were searched a minimum of two times throughout the breeding season (May 24 to July 31). Locations of territorial males and nests were georeferenced with a WAAS enabled, differentially corrected GPS unit (12-channel Garmin, Etrex, $15 \mathrm{~m}$ horizontal accuracy). A total of 30 forest patches were surveyed for breeding S. citrina in 2004. In 2005 however, because of a variety of constraints, we were able to resurvey only 15 of those patches, but we acquired data on nesting S. citrina from another eight forest patches in the area. Three of these forest patches were different from our initial 
set of 30 forest patches (courtesy of the D. Burke, Ministry of Natural Resources, silvicultural study on species at risk). Data for each year were analyzed separately.

\section{Nesting habitat}

To assess whether a forest patch had the potential to function biologically as nesting habitat, standard habitat characteristics were measured around found nests in occupied patches and at selected (or control) vegetation plots in unoccupied forest patches (hereafter pseudo nest plots). Hooded Warblers are known for their easily identifiable nesting habitat preferences (Bisson and Stutchbury 2000, Whittam et al. 2002). They nest in the dense understory shrub layer of small openings in the forest canopy, i.e., with median forest gap sizes between 40 $\mathrm{m}^{2}$ and $300 \mathrm{~m}^{2}$, that are typically created by the death of a large tree or by selection harvesting (Bisson and Stutchbury 2000, Whittam et al. 2002). All selected pseudo nest sites were chosen subjectively to match known $S$. citrina nesting preferences, and these pseudo nest plots were only located in unoccupied forest patches as confirmed by a minimum of two to three bird surveys for singing males during the breeding season.

We surveyed 11 nest-site habitat indicators, e.g., gap dimension, understory structure $(0-3 \mathrm{~m})$, and number of trees (Table 1) within a $5 \mathrm{~m}$ radius plot $(0.0075 \mathrm{ha})$. Gaps were defined as a hole in the forest canopy with an approximate diameter no smaller than $5 \mathrm{~m}$ (Brokaw 1982). Gap size was estimated by eye, visualizing a pair of perpendicular lines fit to the largest dimensions of the gap; $L$, length, was the longest straight line that would fit in the gap and $W$ was the width of a line that would fit perpendicular to the first (Runkle 1992). The area of the gap was estimated using the equation for the area of an ellipse: $A=\pi L W / 4$ (Whittam et al. 2002). Total basal area was estimated using a factor 2 prism for all trees above $10 \mathrm{~cm}$ diameter at breast height, i.e., $1.3 \mathrm{~m}$ (Table 1). Nest-site habitat data for nest and pseudo nest plots were only collected during the year 2004; in 2005, only site context data around occupied and unoccupied patches within $1 \mathrm{~km}$ were used in logistic regressions (see below).

\section{Site-context}

Broad-scale predictor variables were measured within $1 \mathrm{~km}$ (314 ha) of each surveyed patch centroid. This $1 \mathrm{~km}$ extent (hereafter referred to as the 'site-context') was selected to correspond with $S$. citrina daily dispersal or movement tendencies during the breeding season. Female and male $S$. citrina have known dispersal tendencies: females are reluctant to cross nonforest breaks larger than $50 \mathrm{~m}$ in width during the breeding season, whereas males tend to cross larger breaks up to $500 \mathrm{~m}$ in width (Norris and Stutchbury 2002). Ninety-five percent of all male movement forays observed by Norris and Stutchbury (2002) were less than $1 \mathrm{~km}$ in total distance traveled; moreover, there is an expected energetic cost associated with such movement behaviors. Therefore, the size of the site-context around a focal patch was selected to be both larger than the largest observed nonforest crossing distance, i.e., $<500 \mathrm{~m}$, and larger than the distance a bird can be expected to move daily through a fragmented area. Many multiscale studies of birds in different landscapes have examined predictor variables within a similar surrounding area (McGarigal and McComb 1995, Lee et al. 2002, Cushman and McGarigal 2004, Uezu et al. 2005).

\section{Forest cover}

Forest cover was estimated by determining the relative percent cover of forest habitat within the site-context, i.e., within a 1 $\mathrm{km}$ radius of the patch centroid. Forest cover was estimated from Ontario Base Maps (OBM 1996), wooded areas layer $(1: 10,000)$, which was manually updated and checked for accuracy using aerial photographs as described above. Area forested was divided by the total area within the site context (314 ha) to get an estimate of forest cover.

\section{Structural forest connectivity}

We summarized seven measures of structural connectivity within $1 \mathrm{~km}$ of each site: nearest neighboring patch distance $(N N)$, total edge $(T E)$, largest patch area $(L P A)$, nest search area $(S A)$, patch area $(P A)$, mean patch area $(M P A)$, and total number of patches (NP; Table 1). Distance to nearest neighboring patch was considered to be the most direct measure of structural connectivity because it reflects the smallest nonforested opening a bird must cross to reach additional forest habitat. Thus $N N$ provides a direct structural measure of isolation. Other measures of structural connectivity such as total edge and measures of patch size are commonly used metrics of habitat configuration; they perhaps provide an indirect indication of habitat suitability in surrounding patches, which relates to relative habitat isolation (reviewed by Swift and Hannon 2010).

\section{Graph-based forest connectivity}

The functional connectivity of forest patches was estimated using spatial graphs (Fall et al. 2007); patches were connected if the edge-to-edge distance between patches was less than the maximum nonforest crossing distance that $S$. citrina will traverse during the breeding season (Opdam et al. 2003). It is assumed that movements are restricted above these dispersal thresholds (Keitt et al. 1997). To determine amount of connected forest habitat, we computed expected cluster sizes $\left(E C S_{t}\right)$ over the entire study region within $20 \mathrm{~km}$ of the core population of S. citrina. ECS represents the average size of a connected cluster at a given distance threshold for a randomly selected forest habitat cell (Fall et al. 2007). ECS was computed for distance thresholds that matched female and male dispersal tendencies during the breeding season, i.e., 50 and $500 \mathrm{~m}$, respectively, as follows: 


$$
\sum_{E C S_{t}=}^{m} a_{j}^{2} /
$$

$m$ is the number of connected clusters at a given distance threshold $(t) ; a_{j}$ is the area of cluster $j$; and $A$ is the total area of all patches in the region (Fall et al. 2007).

The importance of individual forest patches to the maintenance of connectivity was determined by performing a patch removal analysis at female and male nonforest gap crossing thresholds (Fall et al. 2007). By removing each patch one by one and recalculating $E C S_{t}$, the relative change in this metric can be used to provide an indication of regional patch importance to the maintenance of connectivity for females or males $\left(R P I_{f}\right.$ or $\left.\mathrm{RPI}_{m}\right)$. RPI values were used to map patch importance throughout the study area, and these graph-connectivity rankings were used to select patches with high, medium, and low connectivity as part of the study design.

Eight measures of graph-based functional connectivity were estimated in total (Table 1). Five of these measures were evaluated within the site-context of surveyed patches, i.e., within a $1 \mathrm{~km}$ radius of the surveyed patch centroid: expected cluster size was recalculated within the site context at nonforest gap crossing distances preferred by females $(<50$ $\mathrm{m}, A C_{f}$ ) and males ( $\left.<500 \mathrm{~m}, A C \mathrm{~m}\right)$; patch importance was also recalculated within the site context by performing another patch removal analysis within the site context at female and male nonforest gap crossing distances $\left(P I_{f}\right.$ and $\left.P I_{m}\right)$; and the overall distance threshold $(D T)$ was estimated within the site context. $D T$ is simply the threshold distance required to connect all patches within the site context. Three additional graph-based functional connectivity measures within the study area were used as predictors. Regional patch importance to the maintenance of connectivity within the study area, i.e., within $20 \mathrm{~km}$ of the core population, at both female and male nonforest gap crossing thresholds $\left(R P I_{f}\right.$ and $\left.R P I_{m}\right)$ were used as additional predictors of functional connectivity. These were the same values used to select forest patches for the study. Lastly distance to the core population $(D C)$ was estimated and used as a predictor because historic data suggests that $S$. citrina seem to be expanding their range in southern Ontario from established core areas (Melles et al. 2011). Spatial graph models were implemented in Spatially Explicit Landscape Event Simulator (SELES, www.seles.info; Fall and Fall 2001).

\section{Statistical models}

It is often the case with many regression methods that the number of predictor variables is high, so some sort of reduction in the number of predictors is required (Aguilera et al. 2006). Number of predictor variables was reduced by assessing their importance using uni-variable likelihood ratio test (LRT) scores with logistic regression of nest occurrence, which measures the change in model log likelihood (LL) with or without a variable. We selected variables whose LRT had a $p$-value $<0.25$ as candidates for multivariable models, and we made sure to include variables of known ecological importance (Appendix 1). This is a recommended approach to variable reduction prior to multivariable logistic regression modeling to avoid overfitting (Hosmer and Lemeshow 2000). Inclusion of all predictor variables at once would produce numerically unstable estimates, especially given our small sample size.

Logistic regression was used to assess the relationship between nest occurrence and nest-site habitat, forest cover, and structural or functional connectivity. We used standardized variables in logistic regression to examine the relative importance of these different predictors following an approach advocated by Smith et al. (2009) for linear regression to disentangle effects of habitat loss and configuration. Variables were separated into blocks for sequential multiple regression because this allowed us to isolate the relative improvement of different chunks of variables that were all related to the same factor. Nest-site variables were entered in the first sequential block using forward conditional selection based on the LRT. Forest cover was entered in the second block based on a forward conditional LRT, and in the third block either of the two types of connectivity measures was allowed to enter, also using forward conditional tests. The outputs of multivariable logistic regression are parameter estimates and odds ratios adjusting for all other variables included in the model (Hosmer and Lemeshow 2000). Moreover, odds ratios provide an indication of effect size (Chinn 2000), so they are useful in comparing the relative importance of different variables. Logistic regression models were fit using SPSS (version 20.0).

We were interested in the relative importance of three main factors, nest-site habitat, surrounding forest cover, and surrounding structural or functional habitat connectivity. The number of variables for 2004 model fitting was reduced to 16 predictors for these three factors ( 5 nest-site variables, forest cover, 4 measures of structural connectivity, or 6 measures of graph-based functional connectivity; Appendix 1). The number of variables for 2005 model fitting was reduced to 11 variables (forest cover, 4 measures of structural connectivity, or 6 measures of functional connectivity; Appendix 2). We were interested in finding the strongest predictors for each factor in multivariable models so that we could determine the relative importance of local nest-site habitat, surrounding forest cover, and either measures of structural or graph-based functional connectivity. We expected that graph-based measures would be better predictors of nest occurrence than structural measures of forest connectivity because they take the species dispersal abilities into account. Because we had several predictor variables for each main factor of interest, the predictor variables were strongly correlated and variance 
inflation factors for landscape site-context variables (measured within $1 \mathrm{~km}$ ) were well above 10 (Appendix 1).

A widely known problem for logistic regression is that parameter estimation becomes unstable under conditions of multicollinearity (Hosmer and Lemeshow 2000, Aguilera et al. 2006). Multicollinearity is a known issue for all types of regression, and collinearity is a known issue when it comes to comparing models that attempt to disentangle the effects of habitat loss, or forest cover in this case, and configuration, or connectivity in this case. A variety of methods can be used to address this issue such as dropping collinear variables from the analysis, ridge regression, all possible subsets analyses, or residual and sequential regression (Graham 2003). With independent variable residual regression the less important variable is regressed against the collinear predictor, and the less important variable is replaced by the residuals of this regression to model the response variable (Graham 2003). Smith et al. (2009) show that this type of residual regression leads to biased interpretations of parameter estimates and they advocate using standardized variables and examination of partial regression coefficients. But their findings may not apply to logistic regression. We compare logistic regression models using both unaltered collinear predictor variables and variables modified using independent variable residual regression (as suggested by Graham 2003). In cases where both forest cover and connectivity variables were relevant in the model (according to model LL's), an interaction term between the two variables was also checked for its influence on model log likelihood.

Model-selection was assessed using AIC corrected for small sample sizes (AICc; Burnham and Anderson 2002). Models were fit to correspond with our ecological expectations such that models with nest-site habitat variables were fit first (2004 data). Then, the importance of surrounding forest cover, structural forest connectivity, or graph-based measures was assessed. The weight of evidence for each model, given the data, was assessed using AICc. For 2005 data, a combination of surrounding forest cover, structural forest connectivity, or graph-based measures were fit. The residuals of all final models were examined for spatial autocorrelation.

Although spatial autocorrelation in model residuals can lead to unreliable estimations of parameter significance (Fortin and Dale 2005), autocorrelated residuals can also provide useful information about the presence of remaining autocorrelation in the dependent variable, or the existence of a spatiallydependent process related to the dependent variable that has not been accounted for (Lichstein et al. 2002). We examined autocorrelation in model residuals by examining correlograms of Moran's I coefficient assessed at 10 distance classes with a spatial lag of $600 \mathrm{~m}$. This lag size was selected as prior research showed that $S$. citrina nests tend to be clustered in relation to conspecifics at scales between 240 and $600 \mathrm{~m}$, after controlling for the underlying distribution of nesting habitat
(Melles et al. 2009). Second nesting attempts were excluded from the analysis to avoid a potential lack of spatial independence due to renesting attempts located in the vicinity of the first nest. The overall significance of Moran's $I$ correlograms was determined by permutation and evaluated at an alpha level of 0.05 before the significance of individual distance classes was assessed (Rosenberg 2001; Passage Version 2.0.11.6).

\section{RESULTS}

All occupied patches surveyed in 2005 were also occupied in 2004, but given that a different subset of forest patches were surveyed in both years, and given that nest-site habitat data were only collected in 2004, results are presented for each year separately, and not combined. In 2004, 25 first nests were found in all forest patches, and 36 first nests were found in 2005. These nests were matched with 13 pseudo nest plots in 2004 and 5 unoccupied patches in 2005 for a total sample size of $n=38$ and $n=41$ for 2004 and 2005, respectively. The number of pseudo nest plots in 2004, i.e., subjectively selected nesting habitat plots, was limited by the size and number of unoccupied forest patches. Forest cover in the site-context of 2004 patches ranged from $15.4 \%$ to $53.7 \%$; whereas in 2005 , the range of forest cover was narrower, between $20.0 \%$ and $45.5 \%$ forest cover. Average forest cover for all site-contexts $(n=33)$ was $35.9 \% \pm 9.8 \%$ standard deviations.

\section{Nest-site habitat analysis}

Nesting habitat was an important predictor of nest-occurrence (Table 2). Nest locations selected by $S$. citrina had fewer small saplings $(<2.5 \mathrm{~cm}$ diameter at breast height $[\mathrm{dbh}])$, more large saplings $(2.5-9.9 \mathrm{~cm} \mathrm{dbh})$, and were farther from the forest edge than our selected pseudo nest plots in unoccupied forest patches. The importance of these nesting habitat variables seems largely consistent with the findings of previous research that showed $S$. citrina prefer mature forests with small openings in the forest canopy. They tend to select nest sites with a higher subcanopy (average $6.1 \mathrm{~m}$ in height) and a denser understory than randomly selected control sites nearby (Bisson and Stutchbury 2000). Shrub cover was not an important predictor in any of our models, and this indicates that the subjectively selected pseudo nest plots in unoccupied patches had relatively equivalent levels of shrub cover. However, even though unoccupied patches had what we thought of as similar nesting habitat available, our selection of suitable nesting habitat in these patches differed from $S$. citrina's selection of suitable nesting habitat because some nest-habitat variables were important model predictors. Nestsite habitat models alone, however, were 31.6 (model A1) to 4.7 (model A2) times less likely to fit the data than the 'best' models of nest presence or absence in 2004 (Table 3). A large and significant amount of spatial autocorrelation was present in the residuals of one of these nest-site only models (model A1, Figure 2a). 
Table 2. Logistic regression models for $S$. citrina nest occurrence in $2004(n=38)$ using standardized nest-site variables, forest cover, and structural OR functional connectivity measures. The odds ratio in logistic regression $\left(\mathrm{e}^{\wedge} \mathrm{B}\right)$ is the exponent of a parameter estimate and this provides an indication of effect size when variables are standardized. Generally odds ratios can be interpreted as the increase (or decrease) in the likelihood of (nest) occurrence with a one unit change in the predictor variable. Variable codes and transformations are described in Table 1.

\begin{tabular}{|c|c|c|c|c|c|c|c|c|}
\hline \multirow[b]{2}{*}{ Model } & \multirow[b]{2}{*}{$\begin{array}{l}\text { Variables in } \\
\text { the model }\end{array}$} & \multirow[b]{2}{*}{$B$} & \multirow[b]{2}{*}{ s.e. } & \multirow[b]{2}{*}{$d f$} & \multirow[b]{2}{*}{$e^{\wedge} B$} & \multicolumn{2}{|c|}{$95 \%$ C.I. for $e^{\wedge} B$} & \multirow[b]{2}{*}{$\begin{array}{c}\text { Model } \\
\text { log-likelihood }\end{array}$} \\
\hline & & & & & & Lower & Upper & \\
\hline \multicolumn{9}{|c|}{ A1) Nest-site variables } \\
\hline & sS & -0.98 & 0.45 & 1 & 0.38 & 0.15 & 0.91 & 37.83 \\
\hline & $1 \mathrm{~S}$ & 0.94 & 0.45 & 1 & 2.56 & 1.07 & 6.15 & \\
\hline & Constant & 0.82 & 0.41 & 1 & & & & \\
\hline \multicolumn{9}{|c|}{ A2) Nest-site variables } \\
\hline & $\mathrm{sS}$ & -1.15 & 0.51 & 1 & 0.32 & 0.12 & 0.87 & 31.49 \\
\hline & $1 \mathrm{~S}$ & 1.78 & 0.72 & 1 & 5.95 & 1.46 & 24.23 & \\
\hline & EDGE & 1.47 & 0.70 & 1 & 4.36 & 1.10 & 17.33 & \\
\hline & Constant & 1.12 & 0.50 & 1 & & & & \\
\hline \multicolumn{9}{|c|}{ B1) Nest-site \& forest cover } \\
\hline & $\mathrm{sS}$ & -1.36 & 0.57 & 1 & 0.26 & 0.08 & 0.78 & 35.26 \\
\hline & $\mathrm{FC}$ & 1.18 & 0.46 & 1 & 3.24 & 1.31 & 8.03 & \\
\hline & Constant & 1.04 & 0.47 & 1 & & & & \\
\hline \multicolumn{9}{|c|}{ C1) Nest-site \& structural connectivity } \\
\hline & $\mathrm{sS}$ & -1.50 & 0.59 & 1 & 0.22 & 0.07 & 0.71 & 33.38 \\
\hline & LPA & 1.38 & 0.54 & 1 & 3.97 & 1.39 & 11.36 & \\
\hline & Constant & 0.97 & 0.46 & 1 & & & & \\
\hline \multicolumn{9}{|c|}{ C2a) Nest-site, forest cover, \& structural connectivity } \\
\hline & $\mathrm{sS}$ & -1.50 & 0.59 & 1 & 0.22 & 0.07 & 0.71 & 33.18 \\
\hline & FC & 0.33 & 0.73 & 1 & 1.39 & 0.33 & 5.80 & \\
\hline & LPA & 1.11 & 0.80 & 1 & 3.03 & 0.63 & 14.50 & \\
\hline & Constant & 1.00 & 0.47 & 1 & & & & \\
\hline \multicolumn{9}{|c|}{ C2b) Nest-site, forest cover, \& structural connectivity } \\
\hline & $\mathrm{sS}$ & -1.50 & 0.59 & 1 & 0.22 & 0.07 & 0.71 & 33.18 \\
\hline & $\mathrm{FC}$ & 1.23 & 0.50 & 1 & 3.43 & 1.29 & 9.13 & \\
\hline & LPA_resid ${ }^{\dagger}$ & 0.64 & 0.46 & 1 & 1.90 & 0.77 & 4.67 & \\
\hline & Constant & 1.00 & 0.47 & 1 & & & & \\
\hline \multicolumn{9}{|c|}{ D1) Nest-site \& functional connectivity } \\
\hline & $\mathrm{sS}$ & -1.03 & 0.54 & 1 & 0.36 & 0.12 & 1.02 & 33.41 \\
\hline & $R P I_{m}$ & 1.51 & 0.60 & 1 & 4.53 & 1.39 & 14.70 & \\
\hline & Constant & 1.20 & 0.53 & 1 & & & & \\
\hline \multicolumn{9}{|c|}{ D2a) Nest-site, forest cover, \& functional connectivity } \\
\hline & $\mathrm{sS}$ & -1.21 & 0.58 & 1 & 0.30 & 0.09 & 0.94 & 32.41 \\
\hline & FC & 0.55 & 0.57 & 1 & 1.74 & 0.57 & 5.30 & \\
\hline & $\mathrm{RPI}_{\mathrm{m}}$ & 1.11 & 0.71 & 1 & 3.03 & 0.76 & 12.07 & \\
\hline & Constant & 1.22 & 0.54 & 1 & & & & \\
\hline \multicolumn{9}{|c|}{ D2b) Nest-site, forest cover, \& functional connectivity } \\
\hline & sS & -1.21 & 0.58 & 1 & 0.30 & 0.09 & 0.94 & 32.41 \\
\hline & $\mathrm{FC}$ & 1.25 & 0.50 & 1 & 3.50 & 1.32 & 9.29 & \\
\hline & $\mathrm{RPI}_{\mathrm{m}-} \mathrm{resid}^{\dagger}$ & 0.86 & 0.55 & 1 & 2.36 & 0.81 & 6.90 & \\
\hline & Constant & 1.22 & 0.54 & 1 & & & & \\
\hline \multicolumn{9}{|c|}{ D3) Nest-site \& functional connectivity } \\
\hline & sS & -1.44 & 0.72 & 1 & 0.24 & 0.06 & 0.98 & 28.42 \\
\hline & $\mathrm{RPI}_{\mathrm{f}}$ & 2.37 & 1.14 & 1 & 10.65 & 1.15 & 98.71 & \\
\hline & $\mathrm{RPI}_{\mathrm{m}}$ & 1.94 & 1.08 & 1 & 6.97 & 0.84 & 57.78 & \\
\hline & Constant & 2.71 & 1.31 & 1 & & & & \\
\hline
\end{tabular}

${ }^{\dagger}$ Residuals were calculated for variables with significant linear relationships with forest cover (FC) and these independent residuals were used in modeling (as per Graham 2003). Bold emphasizes coefficients with nonsensical standard errors.

Forest cover, structural or functional connectivity

Amount of forest cover within the site-context was an important predictor of $S$. citrina nest-occurrence in 2004, in addition to nest-site habitat (Table 2, model B1). As expected, the likelihood of nest occurrence increased with amount of surrounding forest cover in the site context. However, this model was 8.7 times less likely than the overall 'best' model, which included a nest-site habitat term as well as two terms 
Table 3. Model selection for models of S. citrina nest occurrence in 2004 (southern Ontario) with nest-site variables and sitecontext measures of forest cover, and structural OR graph-based functional connectivity. Variable codes and transformations as in Table 1. Further model details, e.g., parameter estimates, standard errors, odds ratios, can be found in Table 2.

\begin{tabular}{|c|c|c|c|c|c|c|c|c|}
\hline Model & Variables in the model & $\begin{array}{l}\text { Model log- } \\
\text { likelihood }\end{array}$ & \# vars & $\mathrm{AIC}_{\mathrm{c}}$ & $\begin{array}{c}\text { Delta } \\
\operatorname{AIC}_{\mathrm{c}} \Delta_{\mathrm{i}}\end{array}$ & $\begin{array}{c}\text { Model } \\
\text { likelihood }\end{array}$ & $\begin{array}{c}\text { Akaike } \\
\text { weight } \\
\left(w_{i}\right) \dagger\end{array}$ & $\begin{array}{l}\text { Evidence } \\
\text { ratio } \ddagger\end{array}$ \\
\hline A1) Nest-site variables & $\mathrm{sS}+1 \mathrm{~S}$ & 37.83 & 3 & 44.54 & 6.91 & 0.03 & 0.02 & 31.65 \\
\hline A2) Nest-site variables & $\mathrm{sS}+1 \mathrm{~S}+\mathrm{EDGE}$ & 31.49 & 4 & 40.71 & 3.08 & 0.21 & 0.12 & 4.66 \\
\hline B1) Nest-site \& forest cover & $\mathrm{sS}+\mathrm{FC}$ & 35.26 & 3 & 41.97 & 4.34 & 0.11 & 0.07 & 8.75 \\
\hline C1) Nest-site \& structural connectivity & $\mathrm{sS}+\mathrm{LPA}$ & 33.38 & 3 & 40.09 & 2.46 & 0.29 & 0.17 & 3.42 \\
\hline $\begin{array}{l}\mathrm{C} 2 \mathrm{a} \text { or } \mathrm{C} 2 \mathrm{~b}) \text { Nest-site, forest cover, \& structural } \\
\text { connectivity }\end{array}$ & $\mathrm{sS}+\mathrm{FC}+$ LPA_resid & 33.18 & 4 & 42.40 & 4.77 & 0.09 & 0.05 & 10.84 \\
\hline D1) Nest-site \& functional connectivity & $\mathrm{sS}+\mathrm{RPI}_{\mathrm{m}}$ & 33.41 & 3 & 40.11 & 2.48 & 0.29 & 0.17 & 3.46 \\
\hline $\begin{array}{l}\text { D2a or D2b) Nest-site, forest cover, \& } \\
\text { functional connectivity }\end{array}$ & $\mathrm{sS}+\mathrm{FC}+\mathrm{RPI}_{\mathrm{m}}{ }_{-}$resid & 32.41 & 4 & 41.62 & 3.99 & 0.14 & 0.08 & 7.35 \\
\hline D3) Nest-site \& functional connectivity & $\mathrm{sS}+\mathrm{RPI}_{\mathrm{f}}+\mathrm{RPI}_{\mathrm{m}}$ & 28.42 & 4 & 37.63 & 0.00 & 1.00 & 0.58 & 1.00 \\
\hline \multicolumn{9}{|c|}{$\begin{array}{l}\Delta_{i}=A I C_{c i}-\min \mathrm{AIC}_{c} \\
\dagger w_{i}=\exp \left(-\Delta_{i} / 2\right) / \Sigma \exp (-\Delta r / 2) \text {, where } r \text { is the number of models in the set compared } \\
\ddagger \text { ratio of Akaike weight for model } j \text { to the best model } w_{i}\left(w_{j} / w_{i}\right) \\
\text { Weight of model with the greatest support, given the data, is highlighted in bold type. }\end{array}$} \\
\hline
\end{tabular}

for regional functional connectivity based on female and male $S$. citrina dispersal tendencies $\left(R P I_{f}\right.$ and $R P I_{m}$, Tables 2 and 3 , model D3). In comparison, a model that included an estimate of structural connectivity ( $L P A)$ within the site-context (model $\mathrm{C} 1$ ), in addition to the nest-site term, was 3.4 times less likely than the overall 'best' model according to $\mathrm{AIC}_{\mathrm{c}}$ (i.e., model D3, Tables 2 and 3). Models of nest-site habitat and either a structural variable (model C1) or a functional (model D1) connectivity variable were almost equivalent in terms of model likelihood (Tables 2 and 3).

However, because these and other models did not contain the confounded term, forest cover, the odds ratios for these variables must be interpreted with some care. For example, the odds of finding a nest increased by almost four times with a one unit change in standardized LPA, or area of the largest patch (Table 2, model C1). However, when forest cover was included, their estimated coefficients and odds ratios changed markedly (compare models C1, C2a, C2b, Table 2), which is consistent with their confounded status. Indeed, confidence intervals around the odds ratio for LPA when forest cover was included in the model (C2ab, Table 2) overlapped one, indicating no difference. So the odds of finding a nest either decreased (63\% odds) or increased (by 14.5 times, model C2a, Table 2) with a one unit change in LPA under this model, and this was true for several other models with confounded predictors, e.g., model D2ab and even the 'best' model.

When both unaltered forest cover and unaltered measures of forest connectivity were included, forest cover had nonsensical standard errors around the parameter estimate and the confidence intervals overlapped one (Tables 2 and 4, bolded lines). It is ecologically implausible to then infer that forest cover had no effect on $S$. citrina nest occurrence from these models, but erroneous interpretations are possible with these kinds of results (Hosmer and Lemeshow 2000). In logistic regression, when variables are collinear it becomes difficult to estimate adjusted odds ratios because of the need to invert near singular and ill-conditioned information matrices (Aguilera et al. 2006). There is no unique solution. This is a well-known issue for both linear and logistic regression (Hosmer and Lemeshow 2000). Consequently, odds ratios estimated from multivariate logistic regression with confounded predictors may be erroneous and should be interpreted with care (Aguilera et al. 2006).

When we used the residuals of a regression between forest cover and connectivity (Table 2, models C2b and D2b), our results could actually be interpreted with more clarity, contrary to expectations suggested by Smith et al. (2009) for linear regression. Though the parameter estimate for forest cover in this case includes variation shared between forest cover and the connectivity variable, there was still some slight variation uniquely explained by connectivity alone, independent of forest cover, albeit only marginal and confidence intervals spanned one. These findings were consistent for our analysis of 2005 data as well (Table 4, models C2ab and D2ab). When we checked for interactions between forest cover and structural or functional connectivity variables, interaction terms made no improvement on these model's loglikelihoods.

The 'best' overall model of $S$. citrina breeding-patch occupancy in 2004 was a model that included a nesting habitat variable and two measures of functional connectivity (Tables 2 and 3, model D3). Forest cover was not included in this model, but we know that it is confounded with our measures of connectivity (Appendix 1). $R P I_{m}$ was positively correlated with forest cover (Pearson's correlation coefficient $=0.631, p$ $<0.001)$. The two 'best' overall models in 2005 also included 
Table 4. Logistic regression models for S. citrina nest occurrence in $2005(n=41)$ using standardized forest cover, and structural OR functional connectivity measures. The odds ratio in logistic regression $\left(\mathrm{e}^{\wedge} \mathrm{B}\right)$ is the exponent of a parameter estimate and this provides an indication of effect size when variables are standardized. Generally odds ratios can be interpreted as the increase (or decrease) in the likelihood of (nest) occurrence with a one unit change in the predictor variable. Variable codes and transformations are described in Table 1.

\begin{tabular}{|c|c|c|c|c|c|c|c|c|}
\hline \multirow[b]{2}{*}{ Model } & \multirow[b]{2}{*}{$\begin{array}{l}\text { Variables in } \\
\text { the model }\end{array}$} & \multirow[b]{2}{*}{$B$} & \multirow[b]{2}{*}{ s.e. } & \multirow[b]{2}{*}{$d f$} & \multirow[b]{2}{*}{$e^{\wedge} B$} & \multicolumn{2}{|c|}{$95 \%$ C.I. for $e^{\wedge} B$} & \multirow[b]{2}{*}{$\begin{array}{c}\text { Model } \\
\text { log-likelihood }\end{array}$} \\
\hline & & & & & & Lower & Upper & \\
\hline \multicolumn{9}{|c|}{ B1) Forest cover } \\
\hline & $\mathrm{FC}$ & 0.94 & 0.48 & 1 & 2.57 & 1.00 & 6.63 & 26.19 \\
\hline & Constant & 2.30 & 0.60 & 1 & & & & \\
\hline \multicolumn{9}{|c|}{ C1) Structural connectivity } \\
\hline & LPA & 1.12 & 0.54 & 1 & 3.06 & 1.07 & 8.73 & 24.56 \\
\hline & Constant & 2.38 & 0.62 & 1 & & & & \\
\hline \multicolumn{9}{|c|}{ C2a) Forest cover + structural connectivity } \\
\hline & FC & 0.21 & 0.69 & 1 & 1.24 & 0.32 & 4.74 & 24.46 \\
\hline & LPA & 0.96 & 0.73 & 1 & 2.62 & 0.62 & 11.02 & \\
\hline & Constant & 2.39 & 0.63 & 1 & & & & \\
\hline \multicolumn{9}{|c|}{ C2b) Forest cover + structural connectivity } \\
\hline & $\mathrm{FC}$ & 1.50 & 0.72 & 1 & 4.50 & 1.10 & 18.44 & 24.46 \\
\hline & LPA_resid ${ }^{\dagger}$ & -0.86 & 0.66 & 1 & 0.42 & 0.12 & 1.53 & \\
\hline & Constant & 2.39 & 0.63 & 1 & & & & \\
\hline \multicolumn{9}{|c|}{ D1) Functional connectivity } \\
\hline & $\mathrm{RPI}_{\mathrm{m}}$ & 1.88 & 0.79 & 1 & 6.56 & 1.41 & 30.55 & 20.05 \\
\hline & Constant & 3.15 & 1.01 & 1 & & & & \\
\hline \multicolumn{9}{|c|}{ D2a) Forest cover + functional connectivity } \\
\hline & FC & -0.04 & 0.57 & 1 & 0.96 & 0.31 & 2.93 & 20.04 \\
\hline & RPI & 1.92 & 0.96 & 1 & 6.84 & 1.03 & 45.30 & \\
\hline & Constant & 3.16 & 1.03 & 1 & & & & \\
\hline \multicolumn{9}{|c|}{ D2b) Forest cover + functional connectivity } \\
\hline & $\mathrm{FC}$ & 3.43 & 1.49 & 1 & 30.83 & 1.67 & 570.62 & 20.04 \\
\hline & $\mathrm{RPI}_{\mathrm{m}-} \mathrm{resid}^{\dagger}$ & -2.89 & 1.45 & 1 & 0.06 & 0.00 & 0.95 & \\
\hline & Constant & 3.16 & 1.03 & 1 & & & & \\
\hline \multicolumn{9}{|c|}{ D3) Functional connectivity } \\
\hline & $\mathrm{DC}$ & -0.90 & 0.72 & 1 & 0.41 & 0.10 & 1.68 & 18.39 \\
\hline & $\mathrm{RPI}_{\mathrm{m}}$ & 1.71 & 0.84 & 1 & 5.52 & 1.07 & 28.59 & \\
\hline & Constant & 3.60 & 1.23 & 1 & & & & \\
\hline \multicolumn{9}{|c|}{ D4) Functional connectivity } \\
\hline & $\mathrm{AC}_{\mathrm{m}}$ & 0.83 & 0.51 & 1 & 2.30 & 0.84 & 6.28 & 26.78 \\
\hline & Constant & 2.21 & 0.56 & 1 & & & & \\
\hline
\end{tabular}

Residuals were calculated for variables with significant linear relationships with forest cover (FC) and these independent residuals were used in modelling (Graham 2003). Bold emphasizes coefficients with nonsensical standard errors.

functional connectivity measures alone $\left(R P I_{m}\right.$ and $D C$; Table 5, model D1, D3). A model that included forest cover and the independent variable regression residuals of functional connectivity in 2005 (model D2b) was 3.2 times less likely to explain nest occurrence data than the 'best' model according to $\mathrm{AIC}_{\mathrm{c}}$ scores (Table 5, model D1); and structural connectivity models were 10 times less likely to fit the data (Table 5, model C1).

Odds ratios reported in Table 2 and 4 provide an indication of effect size given that variables were standardized prior to regression analysis (Chinn 2000). We can see that functional connectivity metrics had higher odds ratios in general than structural connectivity measures. The highest odds ratios were reported for functional connectivity metrics in the 'best' models (Table 2 and 4, D3), and nest-site variables had the second highest odds ratios in 2004. Forest cover also had relatively high odds ratios when this variable was included with connectivity residuals. To make more ecological sense out of these odds ratios, we would need to back transform the predictors from their standardized and logarithmic or logit transformed scales.

Figure 2 depicts Moran's I correlograms for models with significant residual autocorrelation. Residual autocorrelation was not a problem for most models, however, two models showed significant autocorrelation, and this was attributed to the first distance class $(<600 \mathrm{~m})$. Besides the nest-site habitat only model, a model with nest-site habitat and regional patch importance $\left(R P I_{m}\right)$ in 2004 had significant Moran's I residual autocorrelation. 
Table 5. Model selection for S. citrina nest occurrence in 2005 (southern Ontario) with standardized site-context measures of forest cover, and structural OR graph-based functional connectivity. Variable codes and transformations as in Table 1. Further model details, e.g., parameter estimates, standard errors, odds ratios, can be found in Table 4.

\begin{tabular}{|c|c|c|c|c|c|c|c|c|}
\hline Model & $\begin{array}{l}\text { Variables in the } \\
\text { model }\end{array}$ & $\begin{array}{l}\text { Model log- } \\
\text { likelihood }\end{array}$ & \#vars & $\mathrm{AIC}_{\mathrm{c}}$ & $\begin{array}{c}\text { Delta } \\
\operatorname{AIC}_{\mathrm{c}} \Delta_{\mathrm{i}}\end{array}$ & $\begin{array}{l}\text { Model } \\
\text { likelihood }\end{array}$ & $\begin{array}{c}\text { Akaike } \\
\text { weight } \\
\left(w_{i}\right) \dagger\end{array}$ & $\begin{array}{l}\text { Evidence } \\
\text { ratio } \neq\end{array}$ \\
\hline B1) Forest cover & $\mathrm{FC}$ & 26.19 & 2 & 30.50 & 6.14 & 0.05 & 0.02 & 21.52 \\
\hline C1) Structural connectivity & LPA & 24.56 & 2 & 28.87 & 4.51 & 0.10 & 0.05 & 9.53 \\
\hline $\begin{array}{l}\mathrm{C} 2 \mathrm{a} \text { or } \mathrm{C} 2 \mathrm{~b} \text { ) Forest cover }+ \text { structural } \\
\text { connectivity }\end{array}$ & FC + LPA_resid & 24.46 & 3 & 31.11 & 6.74 & 0.03 & 0.02 & 29.12 \\
\hline D1) Functional connectivity & $\mathrm{RPI}_{\mathrm{m}}$ & 20.05 & 2 & 24.36 & $\mathbf{0 . 0 0}$ & 1.00 & 0.48 & 1.00 \\
\hline $\begin{array}{l}\text { D2a or D2b) Forest cover + functional } \\
\text { connectivity }\end{array}$ & $\mathrm{FC}+\mathrm{RPI}_{\mathrm{m}-}$ resid & 20.04 & 3 & 26.69 & 2.33 & 0.31 & 0.15 & 3.20 \\
\hline D3) Functional connectivity & $\mathrm{DC}+\mathrm{RPI}_{\mathrm{m}}$ & 18.39 & 3 & 25.04 & 0.67 & 0.71 & 0.34 & 1.40 \\
\hline D4) Functional connectivity & $\mathrm{AC}_{\mathrm{m}}$ & 26.78 & 2 & 31.09 & 6.73 & 0.03 & 0.02 & 28.93 \\
\hline \multicolumn{9}{|c|}{$\begin{array}{l}\Delta_{i}=A I C_{c i}-\min \mathrm{AIC}_{c} \\
\dagger w_{i}=\exp (-\Delta / 2) / \Sigma \exp (-\Delta r / 2) \text {, where } r \text { is the number of models in the set compared } \\
\ddagger \text { ratio of Akaike weight for model } j \text { to the best model } w_{i}\left(w_{J} / w_{i}\right) \text {. } \\
\text { Weight of model with the greatest support, given the data, is highlighted in bold type }\end{array}$} \\
\hline
\end{tabular}

Fig. 2. Moran's $I$ correlograms with global significance at the $p<0.05$ level based on 1000 iterations. a) 2004 nest-site model $(s S+l S$, model A1); b) 2004 nest-site and functional connectivity model $(s S+R P I m$, model D1). Circled points had significant $(p<0.05)$ spatial autocorrelation in that distance class. Numbers above the points refer to the number of pairs in each distance class.
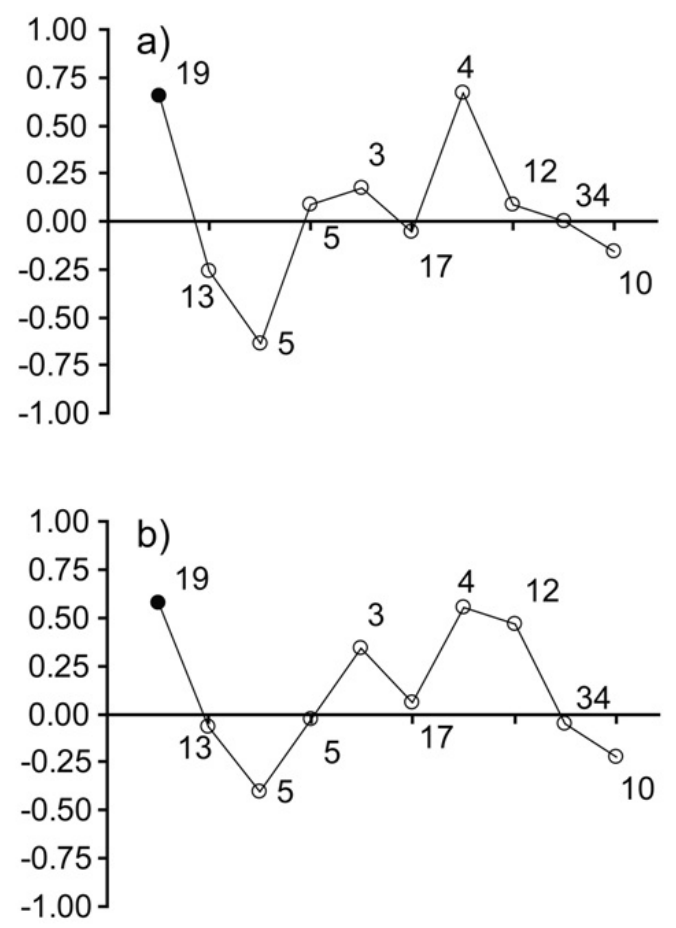

\section{DISCUSSION}

Before we discuss our findings, a note of caution about the limitations of our dataset is warranted here. We investigated the nesting occurrence patterns of a relatively rare species in 33 small forest fragments of southern Ontario and our sample size was correspondingly small ( $n<41$ in both years) with some pseudo-replication because various forest patches had more than one nest. Although we were interested in only three factors: nesting habitat, surrounding forest cover, and connectivity, the number of predictor variables was very high, considering the relatively small sample size (totaling 27 possible predictors; Table 1). Univariate likelihood ratio tests were used to reduce the number of possible predictors in both years to 16 in 2004 and 11 in 2005, but even with this number of predictor variables, the likelihood of finding spurious results is high, especially given that we used forward (block) selection methods (see Mundry and Nunn 2009).

It is for this reason that our results should be considered as exploratory. However, we did not have a one to one mapping of our variables to hypotheses (as per Burnham et al. 2011). We had several variables for each of our three main factors, and these factors were entered as blocks of variables in logistic regression, which meant that the actual number of inferential tests performed during forward block selection was not terribly high for the dataset $(n<20)$. Moreover, we believe that the likelihood of finding spurious results between nesting occurrence and the three main factors of interest in this study is relatively low.

\section{Importance of nesting habitat}

Our results provide some support for the expectation that nestsite characteristics of the environment at fine spatial scales are indeed related to the breeding distribution of S. citrina. This finding is in concordance with the general rule that 
environmental heterogeneity at fine spatial scales influences which species out of the regional source pool settle in an area (Haila 1983). However, a settlement pattern based on nesting habitat alone did not fully explain the data on S. citrina nestsite occurrence. Some of the variance in nest-occurrence patterns can also be attributed to surrounding forest cover and graph-based connectivity measures, albeit one of the nest-site habitat only models was a comparable final model in 2004. This model was only 4.7 times less likely than a model including functional connectivity as a probable explanation for the breeding distribution of S. citrina. Our results are consistent with the findings of several other studies that have looked at the relative importance of local habitat characteristics and surrounding landscape-scale variables (for example, Drapeau et al. 2000, Hagan and Meehan 2002, Cushman and McGarigal 2004). These studies demonstrated that home-range or local-scale variables are equally or more important than surrounding landscape configuration variables though they did not examine functional connectivity per se. For example, Cushman and McGarigal (2004) examined the bird community in 19 landscapes ( $\cong 300$ ha in size) of the Oregon Coast range in a comprehensive variance-partitioning study of the influence of habitat at multiple spatial scales. They found that local-scale variables were better predictors of bird community structure than patch-shape metrics or landscape cover and configuration variables. Because their study was conducted in a predominantly forested region with patches defined by different stages of forest maturity, they suggested that configuration variables may be more important than local habitat factors or surrounding forest cover in areas with greater contrast between forest and nonforest patches. In contrast, our study suggests that habitat parameters at the scale of nest sites may still have a substantial influence on the breeding distribution of $S$. citrina even in an area with great contrast between forest and nonforest patches.

\section{Forest cover and structural or graph-based functional connectivity}

An extensive amount of research has focused on determining the relative importance of landscape cover and landscape configuration on population and community processes (e.g. McGarigal and McComb 1995, Lee et al. 2002, Cushman and McGarigal 2004, Uezu et al. 2005, Betts et al. 2006). The ultimate goal of this type of research is to determine species' response to habitat loss and fragmentation because these are the dominant causes of species decline. We expected that functional connectivity estimates would better capture the response of individuals to landscape structure than common measures of forest structural connectivity, and therefore would better predict $S$. citrina breeding occurrence. So, our goal was to examine whether graph-based estimates of forest functional connectivity, which consider species' dispersal limitations, were better predictors of $S$. citrina breeding occurrence than more typical measures of forest structural connectivity.
Regional patch importance to the maintenance of connectivity at male and female $S$. citrina preferred nonforest gap crossing thresholds were better predictors of nest occurrence in 2004 than surrounding forest cover, but these measures were confounded with forest cover. Indeed, when both forest cover within the site context and the independent effects of regional patch importance $\left(R P I_{m-}\right.$ resid) were included in a model, a one unit increase in either standardized (and transformed) variable increased the odds of observing a nest by 3.5 and 2.4 times, respectively (Table 2, model D2b). The same trends held in 2005, as regional patch importance to the maintenance of connectivity at a male nonforest gap crossing distance threshold was one of the strongest predictors in any model, and this variable was confounded with forest cover. In 2005, however, it was more difficult to tease out the unique effects of forest cover and functional connectivity because parameter estimates for a model with both unaltered predictors made more ecological sense than a model using residuals (Table 4, models D2a and D2b).

These findings have some important implications. Measures of forest connectivity were related to nest occurrence when forest cover was in the model suggesting that high connectivity patches were more well-connected regionally than expected given the amount of forest cover in the site-context. However, we did not find any interaction effects between forest cover and measures of forest connectivity, suggesting that effects of connectivity were not stronger, or weaker, at low levels of habitat. Evidence for interaction effects is inconsistent in the literature (Swift and Hannon 2010) with some studies finding interaction terms were unimportant (Cushman and McGarigal 2003, Radford et al. 2005), and others reporting interactions for some species and not others (e.g., Trzcinski et al. 1999, Betts et al. 2006). Evidence for interaction effects is consistent with the idea that there is a threshold level of habitat loss below which configuration becomes increasingly important.

As graph-based patch importance to regional connectivity (within $20 \mathrm{~km}$ ) often had the highest odds ratios of any models, this suggests that $1-\mathrm{km}$ site-context variables alone may not adequately capture the settlement and nest occurrence patterns of this migratory bird. When $S$. citrina return to their breeding areas during spring migration, they tend to recolonize natal patches and surrounding areas, and their movement patterns are likely to be less restricted during this period than they are during the nesting period. Breeding-site selection is a hierarchical decision making process in birds from the selection of habitat at coarse spatial scales to the selection of a particular forest patch (Block and Brennan 1993). Given that regional estimates of graph-based connectivity were not as restricted as variables limited to the site-context, broader-scale measures may be better estimates of overall settlement preferences in returning migrants. Initial patch settlement upon return from migration should be influenced by the distribution of forest patches in the greater region. This finding 
could also indicate that the typical 'landscape' size, i.e., within $0.5 \mathrm{~km}$ to $2 \mathrm{~km}$ of the focal patch, selected to study the spatial distribution of neotropical migrant birds in fragmented areas may be too small to capture the process of avian recolonization after a return from the wintering grounds. The importance of the variable distance to the core population in one of the 'best' 2005 models corroborates this suggestion because the likelihood of finding a nest decreased with a one unit increase in this standardized and transformed variable by 0.41 times. Therefore, S. citrina nest occurrence was less likely with increasing distance from the core population, suggesting that their extent of occurrence may be expanding from there (see also Melles et al. 2011), but this is an entirely correlative conjecture.

Overall, the more typical structural measures of forest configuration, such as nearest-neighbor, total edge, and patchsize, performed less well in models of nest presence or absence. Betts et al. (2006) studied the independent effects of forest fragmentation on songbirds in New Brunswick and found almost no support for 'pure fragmentation effects' using structural metrics of configuration. In our study, however, graph-based measures of forest connectivity performed reasonably well. Forest cover was a consistently important predictor of nesting occurrence as well.

McGarigal and McComb (1995) found that forest (landscape) cover was a more important predictor than landscape configuration for area sensitive species without exception. A number of other avian studies have also shown that the amount of surrounding forest cover had equal or larger effect sizes than measures of forest configuration (e.g. Trzcinski et al. 1999, Lee et al. 2002, Cushman and McGarigal 2004). However, these studies also emphasized that the relative importance of surrounding forest cover and configuration varies for different bird species. Even so, the comparably strong effect size of our graph-based connectivity measures in relation to the breeding distribution of $S$. citrina requires more consideration.

Graph-based connectivity estimates may be more strongly related to breeding species' distributions relative to structurally-based estimates for several reasons. First, graphbased estimates can be explicitly tied to the species' known dispersal tendencies (Urban and Keitt 2001); this is a substantial improvement over typical measures of landscape configuration. Although there are a variety of ways that configuration can be assessed (McGarigal and McComb 1995, Bender et al. 2003), it is difficult to see how a measure like patch-size, or even nearest-neighboring patch distance, for instance, can truly provide an estimate of landscape configuration that will be relevant for a particular species. In highly fragmented areas where forests are unnaturally and evenly distributed, or in areas where forests are highly clumped, configuration is not necessarily a predictable function of forest cover (contrary to Fahrig 2003, see also Melles et al. 2011). Second, many studies examine relative abundance or presence and absence data rather than actual breeding occurrence patterns. The number of individuals in an area can be a poor indicator of whether or not the species is actually breeding in that area (Van Horne 1983). In this study, graph-based connectivity was a good predictor of breeding occurrence. In a related study, we investigated pairing and breeding success of $S$. citrina in relation to nesting habitat, forest cover, and forest connectivity. Breeding success was more related to habitat characteristics at fine spatial scales than to well-connected forest habitat at larger spatial scales (Melles 2007). Whereas the accessibility of a given forest patch may be an important determinant of species' distribution, nesting success relies on the quality of nesting habitat once a bird reaches a breeding patch. Third, S. citrina seem to cluster their nesting sites in relation to conspecific birds (Melles et al. 2009). Forest patches that are well connected for a particular species should support more nesting conspecifics. S. citrina demonstrates conspecific attraction, hence this species may be more sensitive to forest connectivity.

\section{Recommendations for future research}

Hooded warblers are becoming more abundant in southern Ontario and there is evidence to suggest that they are expanding their range northward. As a result, the Committee on the Status of Endangered Wildlife in Canada recently changed its federal status from 'threatened' to 'not at risk' in May 2012, and the species was down-graded to 'special concern' under the Ontario Endangered Species Act in 2009. The increasing range and abundance of this species presents a good opportunity to further investigate a number of important research questions because detailed data on the species' occurrence patterns through time in southern Ontario now exist. We suggest the following lines of research given the results reported herein. Graph-based connectivity measures were used as a surrogate for functional connectivity and these measures seem to predict breeding occurrence patterns better than structural measures and forest cover, but more evidence is needed to substantiate our results.

- Better account for confounding factors by increasing the selection of forest patches surveyed or monitored and by using statistical methods such as ridge regression (Graham 2003).

- Perform homing experiments under different matrix settings to better understand how both male and female S. citrina respond to different types and amounts of open matrix, i.e., agricultural, rural, roads of different sizes, etc.

- Monitor nesting success and pairing success in forest fragments under different levels of surrounding forest fragmentation to determine if southern Ontario populations are generally sinks. 
- Target effects of connectivity at other levels and components of biodiversity. Design studies that specifically evaluate connectivity and fragmentation impacts on multiple species, entire guilds, and functional groups with similar movement and dispersal abilities.

\section{CONCLUSION}

In the context of species conservation planning, it is important to have a good understanding of species biology to determine how a species interacts with its surroundings. For species like S. citrina, daily movement tendencies and social behaviors seem to be important determinants of settlement patterns in highly fragmented systems. Forest cover was not necessarily an adequate surrogate for functional connectivity on landscapes at or below the theoretical fragmentation threshold of $30 \%$ to $40 \%$ cover. Graph-based methods have theoretical appeal in conservation applications and they may be quite useful for species at risk planning when the species of interest relies on connected habitat.

Responses to this article can be read online at: http://www.ace-eco.org/issues/responses.php/530

\section{Acknowledgments:}

We thank our excellent field associates, Audrey Heagey, Brad McLeod, David Okines, and Paul Woodard. Mary Gartshore, Jon McCracken, and Andrew Couturier also provided much appreciated advice, project management, and GIS assistance. We are grateful to Dawn Burke and the Ontario Ministry of Natural Resources for providing additional field data on $S$. citrina breeding occurrence and nesting success in 2005. A special thanks goes to Dr. Andrew Fall for his work on SELES and spatial graph models, and for all of his kind assistance. Thank you to all of the landowners of Norfolk County that graciously allowed us access to their land and that showed an interest in this work. Without their agreement this study could not have been undertaken. Funding was provided by Environment Canada and Bird Studies Canada through the Hooded Warbler/Acadian flycatcher Recovery Team, with support from: Environment Canada-Ontario Region's Species at Risk program; a PREA Award and an NSERC research grant to M.-J. Fortin; the Frederick Ide Graduate Award, the Reino Freeman scholarship, and an Ontario Graduate Scholarship to S. J Melles. Finally, we would like to acknowledge support provided by the Aquatic Research and Development Section of the Ontario Ministry of Natural Resources, Peterborough, Ontario, Canada.

\section{LITERATURE CITED}

Aguilera, A. M., M. Escabias, and M. J. Valderrama. 2006. Using principal components for estimating logistic regression with high-dimensional multicollinear data. Computational Statistics and Data Analysis 50:1905-1924. http://dx.doi. org/10.1016/j.csda.2005.03.011

Andrén, H. 1994. Effects of habitat fragmentation on birds and mammals in landscapes with different proportions of suitable habitat: a review. Oikos 71:355-366. http://dx.doi. org $/ 10.2307 / 3545823$

Bélisle, M., A. Desrochers, and M.-J. Fortin. 2001. Influence of forest cover on the movements of forest birds: a homing experiment. Ecology 82:1893-1904.

Bender, D. J, L. Tischendorf, and L. Fahrig. 2003. Using patch isolation metrics to predict animal movement in binary landscapes. Landscape Ecology 18:17-39. http://dx.doi. org/10.1023/A:1022937226820

Betts, M. G., G. J. Forbes, A. W. Diamond, and P. D. Taylor. 2006. Independent effects of fragmentation on forest songbirds: an organism-based approach. Ecological Applications 16:1076-1089. http://dx.doi.org/10.1890/1051-0761 (2006)016[1076:IEOFOF]2.0.CO;2

Bisson, I. A., and B. J. M. Stutchbury. 2000. Nesting success and nest-site selection by a neotropical migrant in a fragmented landscape. Canadian Journal of Zoology-Revue Canadienne De Zoologie 78:858-863. http://dx.doi.org/10.1139/z00-009

Block, W. M., and L. A. Brennan. 1993. The habitat concept in ornithology. Pages 35-91 in D. M. Power, editor. Current ornithology. Plenum Press, New York, New York, USA.

Brokaw, N. V. L. 1982. The definition of treefall gap and its effect on measures of forest dynamics. Biotropica 14:158-160. http://dx.doi.org/10.2307/2387750

Brooker, L. C., and M. G. Brooker. 2002. Dispersal and population dynamics of the Blue-breasted Fairy-wren, Malurus pulcherrimus, in fragmented habitat in the Western Australian wheatbelt. Wildlife Research 29:225-233. http://dx. doi.org/10.1071/WR01113

Brooker, L., M. Brooker, and P. Cale. 1999. Animal dispersal in fragmented habitat: measuring habitat connectivity, corridor use, and dispersal mortality. Ecology and Society 3 (1): 4. [online] URL: http://www.consecol.org/vol3/iss1/art4/

Brooks, C. P. 2003. A scalar analysis of landscape connectivity. Oikos 102:433-439. http://dx.doi.org/10.1034/ j.1600-0579.2003.11511.x

Bunn, A. G., D. L. Urban, and T. H. Keitt. 2000. Landscape connectivity: a conservation application of graph theory. 
Journal of Environmental Management 59:265-278. http://dx. doi.org/10.1006/jema.2000.0373

Burnham, K. P., and D. R. Anderson. 2002. Model selection and multi-model inference : a practical information-theoretic approach. Springer, New York, New York, USA.

Burnham, K. P., D. R. Anderson, and K. P. Huyvaert. 2011. AIC model selection and multimodel inference in behavioral ecology: some background, observations, and comparisons. Behavioral Ecology and Sociobiology 65:23-35. http://dx.doi. org/10.1007/s00265-010-1029-6

Cale, P. G. 2003. The influence of social behaviour, dispersal and landscape fragmentation on population structure in a sedentary bird. Biological Conservation 109:237-248. http:// dx.doi.org/10.1016/S0006-3207(02)00152-0

Chinn, S. 2000. A simple method for converting an odds ratio to effect size for use in meta-analysis. Statistics in Medicine 19:3127-3131. http://dx.doi.org/10.1002/1097-0258(20001130) 19:22<3127::AID-SIM784>3.0.CO;2-M

Cushman, S. A., and K. McGarigal. 2003. Landscape-level patterns of avian diversity in the Oregon Coast Range. Ecological Monographs 73:259-281. http://dx.doi. org/10.1890/0012-9615(2003)073[0259:LPOADI]2.0.CO;2

Cushman, S. A., and K. McGarigal. 2004. Hierarchical analysis of forest bird species-environment relationships in the Oregon Coast Range. Ecological Applications 14:1090-1105. http://dx.doi.org/10.1890/03-5131

Desrochers, A., M. Bélisle, J. Morand-Ferron, and J. Bourque. 2011. Integrating GIS and homing experiments to study avian movement costs. Landscape Ecology 26:47-58. http://dx.doi. org/10.1007/s10980-010-9532-8

Desrochers, A., and S. J. Hannon. 1997. Gap crossing decisions by forest songbirds during the post-fledging period. Conservation Biology 11:1204-1210. http://dx.doi.org/10.1046/ j.1523-1739.1997.96187.x

Drapeau, P., A. Leduc, J.-F. Giroux, J.-P. L. Savard, Y. Bergeron, and W. L. Vickery. 2000. Landscape-scale disturbances and changes in bird communities of boreal mixed-wood forests. Ecological Monographs 70:423-444. http://dx.doi.org/10.1890/0012-9615(2000)070[0423:LSDACI] 2.0.CO:2

Dunford, W., and K. Freemark. 2004. Matrix matters: effects of surrounding land uses on forest birds near Ottawa, Canada. Landscape Ecology 20:497-511. http://dx.doi.org/10.1007/ s10980-004-5650-5

Evans Ogden, L. J., and B. J. M. Stutchbury. 1994. Hooded Warbler. Page 20 in A. Poole, P. Stettenheim, and F. Gill, editors. The birds of North America. Vol. No. 110. American Ornithologists' Union, Washington, D.C., USA.

Ewers, R. M., and R. K. Didham. 2006. Confounding factors in the detection of species responses to habitat fragmentation. Biological Reviews 81:117-142. http://dx.doi.org/10.1017/ $\underline{\text { S1464793105006949 }}$

Fahrig, L. 2001. How much habitat is enough? Biological Conservation 100:65-74. http://dx.doi.org/10.1016/S0006-3207 (00)00208-1

Fahrig, L. 2003. Effects of habitat fragmentation on biodiversity. Annual Review of Ecology, Evolution, and Systematics 34:487-515. http://dx.doi.org/10.1146/annurev. ecolsys.34.011802.132419

Fall, A., and J. Fall. 2001. A domain-specific language for models of landscape dynamics. Ecological Modelling 141:1-18. http://dx.doi.org/10.1016/S0304-3800(01)00334-9

Fall, A., M.-J. Fortin, M. Manseau, and D. O'Brien. 2007. Spatial graphs: principles and applications for habitat connectivity. Ecosystems 10:448-461. http://dx.doi.org/10.1007/ s10021-007-9038-7

Fischer, J., and D. B. Lindenmayer. 2007. Landscape modification and habitat fragmentation: a synthesis. Global Ecology and Biogeography 16:265-280. http://dx.doi. org/10.1111/j.1466-8238.2007.00287.x

Fortin, M.-J., B. Boots, F. Csillag, and T. K. Remmel. 2003. On the role of spatial stochastic models in understanding landscape indices in ecology. Oikos 102:203-212. http://dx. doi.org/10.1034/j.1600-0706.2003.12447.x

Fortin, M.-J., and M. R. T. Dale. 2005. Spatial analysis: a guide for ecologists. Cambridge University Press, Cambridge, UK.

Freemark, K. E., and B. Collins. 1992. Landscape ecology of birds breeding in temperate forest fragments. Pages 443-454 in J. M. Hagen, III, and D. W. Johnston, editors. Ecology and conservation of neotropical migrant landbirds. Smithsonian Institution Press, Washington, D.C., USA.

Friesen, L., M. Cadman, P. Carson, K. Elliott, M. Gartshore, M. Martin, J. McCracken, J. Oliver, P. Prevett, B. Stutchbury, D. Sutherland, and A. Woodliffe. 2000. National recovery plan for the Acadian flycatcher (Empidonax virescens) and Hooded Warbler (Wilsonia citrina). National Recovery Plan No. 20, Recovery of Nationally Endangered Wildlife (RENEW), Ottawa, Ontario, Canada.

Graham, M. H. 2003. Confronting multicollinearity in ecological multiple regression. Ecology 84:2809-2815. http:// dx.doi.org/10.1890/02-3114 
Hagan, J. M., and A. L. Meehan. 2002. The effectiveness of stand-level and landscape-level variables for explaining bird occurrence in an industrial forest. Forest Science 48:231-242.

Haila, Y. 1983. Land birds on northern islands: a sampling metaphor for insular colonization. Oikos 41:334-351. http:// dx.doi.org/10.2307/3544092

Hargis, C. D., J. A. Bissonette, and J. L. David. 1998. The behavior of landscape metrics commonly used in the study of habitat fragmentation. Landscape Ecology 13:167-186. http:// dx.doi.org/10.1023/A:1007965018633

Hosmer, D. W., and S. Lemeshow. 2000. Applied logistic regression. John Wiley, New York, New York, USA.

Keitt, T. H., D. L. Urban, and B. T. Milne. 1997. Detecting critical scales in fragmented landscapes. Conservation Ecology 1(1): 4 [online] URL: http://www.consecol.org/vol1/ iss $1 /$ art4/

Koper, N., F. K. A. Schmiegelow, and E. H. Merrill. 2007. Residuals cannot distinguish between ecological effects of habitat amount and fragmentation: implications for the debate. Landscape Ecology 22:811-820. http://dx.doi.org/10.1007/ s10980-007-9083-9

Lee, M., L. Fahrig, K. Freemark, and D. J. Currie. 2002. Importance of patch scale vs landscape scale on selected forest birds. Oikos 96:110-118. http://dx.doi.org/10.1034/

j.1600-0706.2002.960112.x

León-Cortés, J. L., J. J. Lennon, and C. D. Thomas. 2003. Ecological dynamics of extinct species in empty habitat networks. 1. The role of habitat pattern and quantity, stochasticity and dispersal. Oikos 102:449-464. http://dx.doi. org/10.1034/j.1600-0706.2003.12129.x

Lichstein, J. W., T. R. Simons, S. A. Shriner, and K. E. Franzreb. 2002. Spatial autocorrelation and autoregressive models in ecology. Ecological Monographs 72:445-463. http://dx.doi.org/10.1890/0012-9615(2002)072[0445:SAAAMI] 2.0.CO;2

McGarigal, K., and W. C. McComb. 1995. Relationships between landscape structure and breeding birds in the Oregon coast range. Ecological Monographs 65:235-260. http://dx. doi.org/10.2307/2937059

Melles, S. J. 2007. Effects of forest connectivity, habitat availability, and intraspecific biotic processes on range expansion: Hooded Warbler (Wilsonia citrina) as a model species. Dissertation. University of Toronto, Toronto, Ontario, Canada.

Melles, S. J., D. Badzinski, F. Csillag, M.-J. Fortin, and K. Lindsay. 2009. Disentangling habitat and social drivers of nesting patterns in songbirds. Landscape Ecology 24:519-531. http://dx.doi.org/10.1007/s10980-009-9329-9

Melles, S. J., M.-J. Fortin, K. Lindsay, and D. Badzinski. 2011. Expanding northward: influence of climate change, forest connectivity, and population processes on a threatened species' range shift. Global Change Biology 17:17-31. http:// dx.doi.org/10.1111/j.1365-2486.2010.02214.x

Mönkkönen, M., and P. Reunanen. 1999. On critical thresholds in landscape connectivity: a management perspective. Oikos 84:302-305. http://dx.doi.org/10.2307/3546725

Mundry, R., and C. L. Nunn. 2009. Stepwise model fitting and statistical inference: turning noise into signal pollution. American Naturalist 173:119-123. http://dx.doi.org/10.1086/593303

Norris, D. R., and B. J. M. Stutchbury. 2001. Extraterritorial movements of a forest songbird in a fragmented landscape. Conservation Biology 15:729-736. http://dx.doi.org/10.1046/ j.1523-1739.2001.015003729.x

Norris, D. R., and B. J. M. Stutchbury. 2002. Sexual differences in gap-crossing ability of a forest songbird in a fragmented landscape revealed through radiotracking. Auk 119:528-532.

Norton, M. R., S. J. Hannon, and F. K. A. Schmiegelow. 2000. Fragments are not islands: patch vs landscape perspectives on songbird presence and abundance in a harvested boreal forest. Ecography 23:209-223. http://dx.doi.org/10.1111/j.1600-0587.2000. $\underline{\text { tb00277.x }}$

O'Brien, D., M. Manseau, A. Fall, and M.-J. Fortin. 2006. Testing the importance of spatial configuration of winter habitat for woodland caribou: an application of graph theory. Biological Conservation 130:70-83. http://dx.doi.org/10.1016/ j.biocon.2005.12.014

Ontario Base Map (OBM). 1996. Ontario Base Map Data: Wooded area 2003-2006. Ontario Ministry of Natural Resources, Peterborough, Ontario, Canada.

Opdam, P., J. Verboom, and R. Pouwels. 2003. Landscape cohesion: an index for the conservation potential of landscapes for biodiversity. Landscape Ecology 18:113-126. http://dx. doi.org/10.1023/A:1024429715253

Radford, J. Q., A. F. Bennett, and G. J. Cheers. 2005. Landscape-level thresholds of habitat cover for woodlanddependent birds. Biological Conservation 124:317-337. http://dx.doi.org/10.1016/j.biocon.2005.01.039

Rosenberg, M. S. 2001. PASSAGE. Pattern Analysis, Spatial Statistics, and Geographic Exegesis. Version 1.1.2.3. Department of Biology, Arizona State University, Tempe, Arizona, USA.

Runkle, J. R. 1992. Guidelines and sample protocol for sampling forest gaps. U.S. Forest Service General Technical 
Report PNW-GTR-283, Forest Service, Portland, Oregon, USA.

Russell, R. E., R. K. Swihart, and Z. L. Feng. 2003. Population consequences of movement decisions in a patchy landscape. Oikos 103:142-152. http://dx.doi.org/10.1034/ j.1600-0706.2003.12418.x

Smith, A. C., N. Koper, C. M. Francis, and L. Fahrig. 2009. Confronting collinearity: comparing methods for disentangling the effects of habitat loss and fragmentation. Landscape Ecology 24:1271-1285. http://dx.doi.org/10.1007/s10980-009-9383-3

St-Louis, V., M.-J. Fortin, and A. Desrochers. 2004. Spatial association between forest heterogeneity and breeding territory boundaries of two forest songbirds. Landscape Ecology 19:591-601. http://dx.doi.org/10.1023/B:

LAND.0000042849.63040.a9

Swift, T. L., and S. J. Hannon. 2010. Critical thresholds associated with habitat loss: a review of the concepts, evidence, and applications. Biological Reviews 85:35-53. http://dx.doi.org/10.1111/j.1469-185X.2009.00093.X

Taylor, P. D., L. Fahrig, K. Henein, and G. Merriam. 1993. Connectivity is a vital element of landscape structure. Oikos 68:571-573. http://dx.doi.org/10.2307/3544927

Tischendorf, L., and L. Fahriga. 2000. How should we measure landscape connectivity? Landscape Ecology 15:633-641. http://dx.doi.org/10.1023/A:1008177324187

Tischendorf, L., and L. Fahrigb. 2000. On the usage and measurement of landscape connectivity. Oikos 90:7-19. http:// dx.doi.org/10.1034/j.1600-0706.2000.900102.x

Trzcinski, M. K., L. Fahrig, and G. Merriam. 1999. Independent effects of forest cover and fragmentation on the distribution of forest breeding birds. Ecological Applications 9:586-593. http://dx.doi.org/10.1890/1051-0761(1999)009 [0586:IEOFCA]2.0.CO;2

Uezu, A., J. P. Metzger, and J. M. E. Vielliard. 2005. Effects of structural and functional connectivity and patch size on the abundance of seven Atlantic Forest bird species. Biological Conservation 123:507-519. http://dx.doi.org/10.1016/j.

biocon.2005.01.001

Urban, D., and T. Keitt. 2001. Landscape connectivity: a graph-theoretic perspective. Ecology 82:1205-1218. http://dx. doi.org/10.1890/0012-9658(2001)082[1205:LCAGTP]2.0.CO;2

Van Horne, B. 1983. Density as a misleading indicator of habitat quality. Journal of Wildlife Management 47:893-901. http://dx.doi.org/10.2307/3808148

Villard, M. A., M. K. Trzcinski, and G. Merriam. 1999. Fragmentation effects on forest birds: relative influence of woodland cover and configuration on landscape occupancy.
Conservation Biology 13:774-783. http://dx.doi.org/10.1046/ j.1523-1739.1999.98059.x

Whittam, R. M., J. D. McCracken, C. M. Francis, and M. E. Gartshore. 2002. The effects of selective logging on nest-site selection and productivity of Hooded Warblers (Wilsonia citrina) in Canada. Canadian Journal of Zoology-Revue Canadienne De Zoologie 80:644-654. http://dx.doi. org/10.1139/z02-039

With, K. A., and A. W. King. 2001. Analysis of landscape sources and sinks: the effect of spatial pattern on avian demography. Biological Conservation 100:75-88. http://dx. doi.org/10.1016/S0006-3207(00)00209-3 
Appendix 1. Candidate independent predictor variables for models of nest occurrence in 2004. Variables highlighted in bold were selected for further multivariable logistic regression based on significance of univariable likelihood ratio tests and ecological interest. Note the high variance inflation factors (VIF) for landscape variables. Variable codes and descriptions in Table 1.

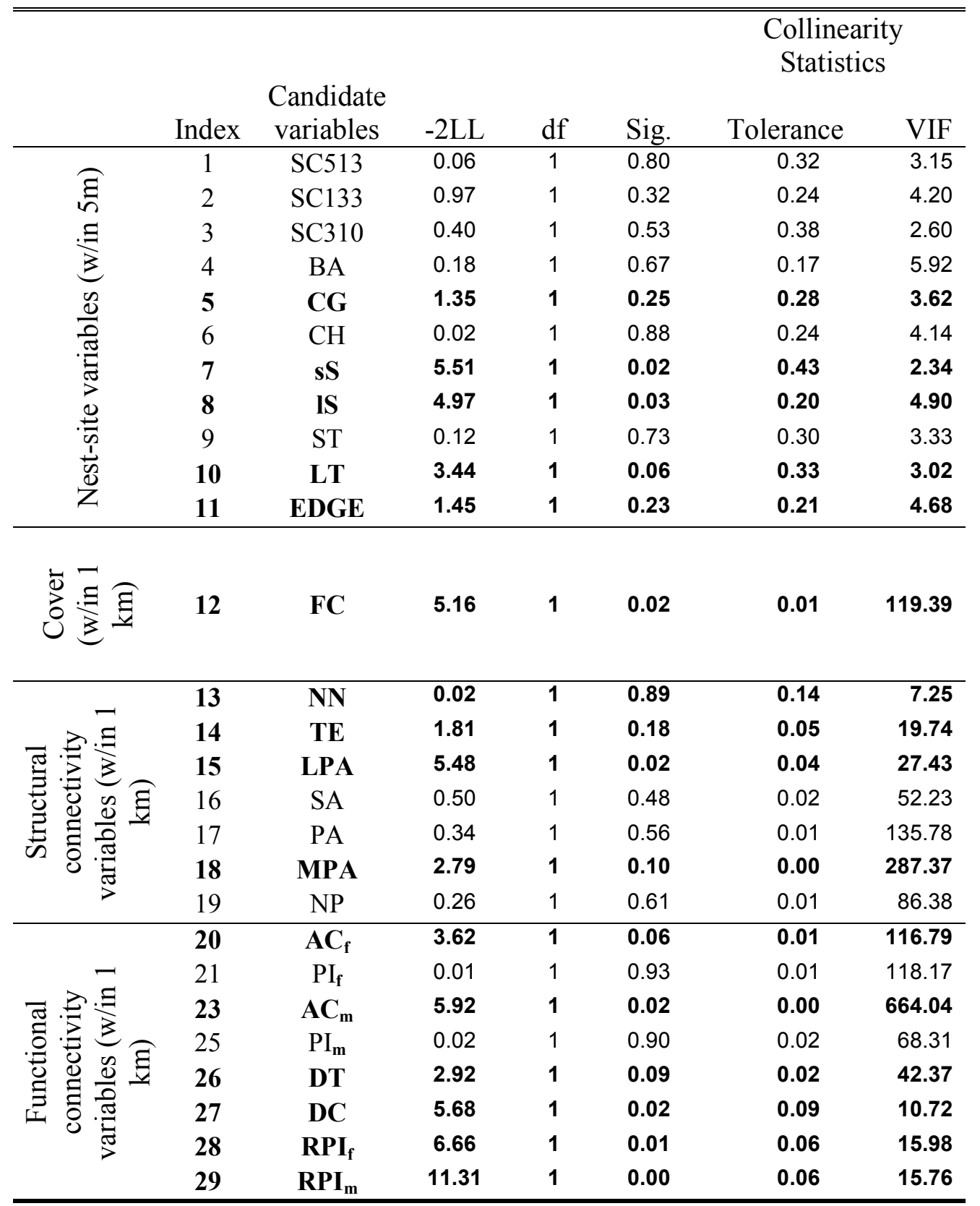


Appendix 2. Candidate independent predictor variables for models of nest occurrence in 2005. Variables highlighted in bold were selected for further multivariable logistic regression based on significance of univariable likelihood ratio tests and ecological interest. Note the high variance inflation factors (VIF) for landscape variables. Variable codes and descriptions in Table 1.

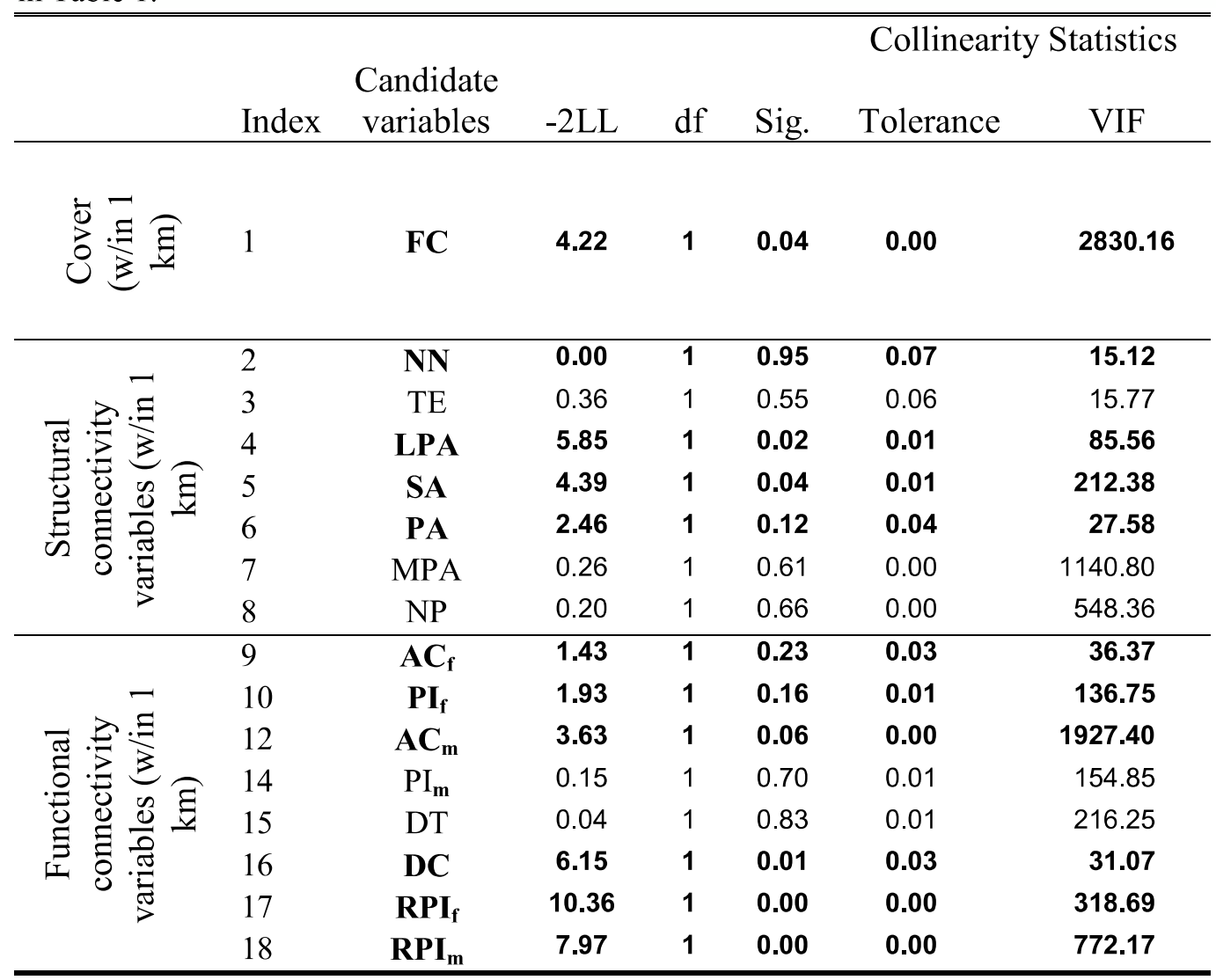

